\title{
Clarithromycin resistance and 23S rRNA gene point mutations of Helicobacter pylori infection in children
}

\author{
Yeliz Çağan-Appak ${ }^{1}$, Hörü Gazi², Semin Ayhan ${ }^{3}$, Beyhan Cengiz-Özyurtt ${ }^{4}$, Semra Kurutepe ${ }^{2}$, \\ Erhun Kasirga ${ }^{1}$ \\ ${ }^{1}$ Division of Pediatric Gastroenterology, Department of Pediatrics, Departments of ${ }^{2}$ Microbiology, ${ }^{3}$ Pathology, and ${ }^{4}$ Public \\ Health, Celal Bayar University Faculty of Medicine, Manisa, Turkey. \\ E-mail: yelizcagan@yahoo.com \\ Received: 17th May 2016, Revised: 11th July 2016, Accepted: 20th October 2016
}

SUMMARY: Çağan-Appak Y, Gazi H, Ayhan S, Cengiz-Özyurt B, Kurutepe S, Kasırga E. Clarithromycin resistance and 23S rRNA gene point mutations of Helicobacter pylori infection in children. Turk J Pediatr 2016; 58: 371-376.

This study aims to evaluate Helicobacter pylori with clarithromycin resistant genotypes in Manisa region, Turkey. Two hundred patients, who received diagnosis of Helicobacter pylori infection histopathologically, were included. The sex, age and endoscopy indications of the patients were recorded. Polymerase chain reaction method was applied to determine the clarithromycin resistance rate and resistance genotypes at the histologic sections prepared from gastric biopsies that had been embedded in paraffin after fixation by formalin. Helicobacter pylori resistance to clarithromycin was found in 19/200 (9.5\%) patients. 10/19 (52.6\%) of these clarithromycin-resistant patients had A2143G mutation and 9/19 (47.4\%) had A2142G mutation. A2142C mutation on 23S rRNA gene was not detected for any of the patients. Clarithromycin can be used as a first step treatment in the eradication of Helicobacter pylori for the children in our region; if the treatment fails for some patients, clarithromycin resistance, especially A2143G and A2142G mutations should be considered.

Key words: Helicobacter pylori, clarithromycin, genotype, polymerase chain reaction, child.

Helicobacter pylori (H. pylori) infection plays an important role in the development of chronic active gastritis, gastric and duodenal ulcer for both children and adults ${ }^{1,2}$. Getting H. pylori at an early age is an important risk factor in development of gastric adenocarcinoma and mucosa-related lymphoid tissue (MALT)

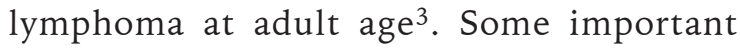
complications that may accompany $H$. pylori infections during childhood are iron deficiency anemia resistant to treatment, short stature, autoimmune diseases and idiopathic thrombocytopenic purpura. Prevalence of $H$. pylori infection is $70-90 \%$ in developing countries and $25-50 \%$ in developed countries ${ }^{4}$. In our country $30-56.6 \%$ of children get infected with $H$. pylori and detection and treatment of the disease during childhood is important for preventing complications ${ }^{5}$. In the recent years, the highest level of success in eradication of H. pylori has been $70 \%{ }^{6}$. Clarithromycin has an important place among many treatment protocols offered for eradication of $H$. pylori. However, the increase of strains resistant to clarithromycin decreases the success level of eradication treatment ${ }^{7}$. The numbers of studies about children are less than those about adults on this subject in the literature. The objective of this study is to determine the clarithromycin resistance ratio and genotypic clarithromycin resistance for children with $H$. pylori in the Manisa region.

\section{Material and Methods}

\section{Patients}

The study included 200 patients, retrospectively, aged between 4 and 18 years, who had consulted at Celal Bayar University Medical Faculty Pediatric Gastroenterology Department between May 2009-June 2014, and underwent gastrointestinal system (GIS) endoscopy. The patients included in the study were selected 
from the patients that were $H$. pylori positive according to the histopathological results. The patients who had previously received $H$. pylori eradication treatment, and proton pump inhibitor (PPI) and antibiotics treatment within the 8 weeks prior to endoscopy were not included in the study. The study was carried out between September 2014- July 2015. The study was accepted by the local scientific ethics committee of Celal Bayar University Medical Faculty, Manisa, Turkey. Permission was obtained from the child's parents for the study and endoscopic procedure. The sex, age and endoscopy indications of the patients were recorded from the demographic data of the patients.

Assessment of routine Upper GIS endoscopy and pathology for Helicobacter pylori

Olympus GIF-Q150 gastrointestinal videoscope (Olympus Corporation, Tokyo, Japan) was used to perform an upper GIS endoscopy to the patients. Gastric biopsy specimens were taken from antrum (two), incisura angularis (one) and corpus (two). These specimens were fixed in Hollande's solution in bottles as soon as they were taken from the patient. Following the routine biopsy follow-up, the specimens were properly placed vertically on the mucosa surface, embedded in paraffin and sections were taken from 3 levels. The sections were stained with Hematoxylin-Eosin (H\&E) for histopathological examination and also with Toluidin Blue for detection of $H$. pylori. In the microscopic assessment, the antrum and corpus biopsies were scored separately using visual scala in accordance with the "Updated Sydney System" evaluation criteria. Consequent to scoring chronic inflammatory infiltration in lamina propria, epithelial neutrophilic infiltration, atrophy, intestinal metaplasia and
H. pylori colonization degrees were defined separately.

\section{Preparing section at paraffin blocks}

In the course of the study, following upper GIS endoscopy routine biopsy specimens were forwarded to pathology for histopathological assessment and formalin-fixed, paraffinembedded antrum and corpus biopsies, preserved in the pathology department, of the $200 \mathrm{H}$. pylori positive patients were incorporated in the study. For detection of polymerase chain reaction (PCR), paraffinized sections of 10 micron thick were taken from blocks containing antrum and corpus biopsies of each case.

DNA isolation and detection of clarithromycin resistance

After deparaffinization of paraffinized sections, QIAamp ${ }^{\circledR}$ kit (Qiagen, Hilden, Germany) was used for DNA isolation. Three-point mutations (A2143G, A2142G, A2142C) of H.pylori 23S rRNA, responsible for clarithromycin resistance were detected by Geno Type ${ }^{\circledR}$ HelicoDR kit (Hain Lifescience, Nehren, Germany) using PCR method. The kit was used in accordance with the instructions of the producing company. The strips generating $H$. pylori and 23S band were evaluated in terms of resistance mutation. The samples were considered to be sensitive to clarithromycin when 23 SWT (wild type) band occurred but mutation band did not appear and resistant to clarithromycin when any of the mutation bands appeared but 23 SWT did not occur.

\section{Statistical Analysis}

The data was assessed using descriptive statistics (number, percentage distribution, mean, standard deviation), chi-square and Fisher's exact test. $\mathrm{p}<0.05$ was taken as significance level.

Table I. Clarithromycin Resistance and Endoscopy Indications

\begin{tabular}{|c|c|c|c|c|c|}
\hline \multirow[t]{3}{*}{$\begin{array}{l}\text { Clarithromycin } \\
\text { resistance }\end{array}$} & & \multirow[t]{3}{*}{ No } & \multicolumn{3}{|c|}{ Yes } \\
\hline & & & \multicolumn{3}{|c|}{ Clarithromycin resistance mutation } \\
\hline & & & A2143G & A2142G & A2142C \\
\hline \multirow{2}{*}{$\begin{array}{l}\text { Endoscopy } \\
\text { indications }\end{array}$} & $\begin{array}{c}\text { Dyspepsia } \\
\text { n/total }(\%)\end{array}$ & $141 / 158(89.2)$ & $10 / 158(6.3)$ & $7 / 158(4.4)$ & - \\
\hline & $\begin{array}{l}\text { Abdominal pain } \\
\text { n/total }(\%)\end{array}$ & $15 / 17(88.2)$ & - & 2/17 (11.8) & - \\
\hline
\end{tabular}




\section{Results}

One hundred twenty seven of the 200 patients were girls $(63.5 \%)$ and 72 were boys (36.5\%), their mean age was $13.24 \pm 2.99$ years. Upper GIS endoscopy indications were dyspepsia $(79 \%)$, anemia $(10 \%)$, abdominal pain $(8.5 \%)$ and GIS bleeding (2.5\%). H. pylori resistance to clarithromycin was found in $19 / 200(9.5 \%)$ patients. 10/19 (52.6\%) of these clarithromycinresistant patients had A2143G mutation and 9/19 (47.4\%) had A2142G mutation. A2142C mutation was not detected for any of the patients.

Clarithromycin resistance was observed for the dyspepsia group $17 / 158$ (10.7\%), abdominal pain group 2/17 (11.8\%). Clarithromycin resistance was not seen in anemia and GIS bleeding groups (Table I). A meaningful correlation was not set between upper GIS endoscopy indications and detection of clarithromycin resistance $(\mathrm{p}=0.38)$. Gastritis was determined for 151/181 (83\%) and peptic ulcer was determined for $22 / 181$ $(12 \%)$ patients who had no clarithromycin resistant mutation. All of the clarithromycin resistant patients had gastritis, only four of them had duodenal ulcers. But there was no statistically significant relationship between clarithromycin resistance mutation and the presence of peptic ulcer $(\mathrm{p}=0.28)$ or gastritis $(\mathrm{p}=0.08)$ (Table II).

\section{Discussion}

The standard treatment of $H$. pylori eradication usually includes a triple treatment, which is a combination of PPI, amoxicillin and clarithromycin or metronidazole ${ }^{8}$. The most important reason behind the failure of treatment is the inconsistent medication and the resistance that develops against antibiotics. For many kinds of treatment, clarithromycin plays a key role in eradication of $H$. pylori. The worldwide increase of clarithromycin resistance reduces the ratio of success in $H$. pylori treatment ${ }^{9}$. According to the Maastricht IV/ Florance consensus report, $15-20 \%$ is accepted as the threshold value to determine the regions having high or low clarithromycin resistance ${ }^{6}$. For regions where clarithromycin resistance is over $15-20 \%$, the triple treatment including PPI and clarithromycin is not suggested to be used without making clarithromycin sensitivity tests $^{6}$.

Studies on adults in many countries reveal that $H$. pylori clarithromycin resistance varies between $2.1 \%$ and $30 \%^{7,10-13}$. In Turkey, clarithromycin resistance ratio is reported to vary between $5.4 \%-48.2 \%$ by using different methods ${ }^{14-16}$. A study in Turkey in 2004 included $102 \mathrm{H}$. pylori positive children and clarithromycin resistance was detected for $18.2 \%$ of the patients and with the first step treatment involving clarithromycin, eradication was attained for $75.5 \%$ of those patients ${ }^{17}$. Another study carried out in Izmir, which is a neighboring city of Manisa, in 2012 included 44 children and clarithromycin resistance was found to be $25.7 \%$ and $H$. pylori eradication could be attained for $46.4 \%$ of the patients, who received standard treatment comprising clarithromycin $^{18}$. In 2014, 89 children were included in another study from a different part of Turkey and clarithromycin resistance was found to be $23.5 \%^{19}$. Factors such as the use of different methods, different ratios in using antibiotics for regions and the experience of people applying the method can be effective in identifying different resistant ratios in studies ${ }^{20}$. While clarithromycin resistance ratio differs from region to region, it is a fact that the resistance ratio has increased throughout the years. The increase in clarithromycin resistance in our country and the world is connected to

Table II. Relation Between Clarithromycin Resistance Mutation and Duodenal Ulcers/Gastritis

\begin{tabular}{cccc}
\hline \multirow{2}{*}{ Ulcer } & \multicolumn{2}{c}{ Clarithromycin resistance mutation } & \multirow{2}{*}{$\mathrm{p}^{*}$} \\
\hline$(+) \mathrm{n}(\%)$ & $4 / 19(21)$ & $(-) \mathrm{n} /$ total $(\%)$ & \multirow{2}{*}{0.28} \\
$(-) \mathrm{n}(\%)$ & $15 / 19(79)$ & $159 / 181(88)$ & \\
Gastritis & & & \multirow{2}{*}{0.08} \\
$(+) \mathrm{n}(\%)$ & $19 / 19(100)$ & $151 / 181(83)$ & \\
$(-) \mathrm{n} \mathrm{( \% )}$ & 0 & $30 / 181(17)$ & \\
\hline
\end{tabular}

*Fisher's exact test 
its frequent use particularly in respiratory tract infections ${ }^{21,22}$. In our country, the unnecessary and non-prescribed use of antibiotics can be an important problem and this can explain regional differences.

Clarithromycin is a bacteriostatic antibiotic, belonging to macrolide group and connecting to peptidyl transferase region of 23S ribosomal RNA (rRNA) molecule V domain. In the Western countries, three point mutation (A2143G, A2142G, A2142C) in the V domain of $23 \mathrm{~S}$ rRNA is responsible for more than $90 \%$ of adult cases for clarithromycin resistance ${ }^{23}$. These three mutations, where adenine residue changes place with guanine at 2143 and 2142 positions or with cytosine (A2142C) at 2142 position, are localized at 23S rRNA's peptidyl transferase region ${ }^{24}$. As a result of these point mutations, clarithromycin cannot get connected to ribosomes and cannot be effective. Because of the technical difficulties in culture and antibiogram implementations of $H$. pylori and because it is a fastidious microorganism, practical, cheap and applicable methods are required ${ }^{25}$. Molecular diagnosis tests are alternative methods that are easily standardized and are faster than culture based tests ${ }^{7}$. PCR, one of the molecular diagnosis methods, shows clarithromycin resistance with quite a high sensitivity of $98 \%^{26}$. PCR is a successfully applicable method in showing point mutations that are the causes of clarithromycin resistance in formalin-fixed, paraffin-embedded gastric biopsies in the archive ${ }^{27}$. It is an advantage of this method to be able to determine the possible effect of clarithromycin resistance in the failure of treatment through the biopsy samples of previously applied treatments retrospectively. It is reported that concerning the formalin-fixed, paraffin-embedded gastric biopsies, the sensitivity of the PCR method can be enhanced through optimal control of time of fixation by formalin and proper choice of paraffin sections ${ }^{28}$. PCR method is particularly more effective in identifying H.pylori infection for cases having less number of bacteria ${ }^{28}$.

In our study, mutation A2142C was not found in any patient, A2143G and A2142G mutations were found to be the most frequent. There are several other studies whose results are consistent with our study $20,28,29-31$. The eradication ratio was lower for patients detected to have A2143G mutation ${ }^{29}$. Other studies about the use of clarithromycin in the eradication treatment of $H$. pylori assert that the existence of A2143G mutation negatively effects the treatment process 27,30 . Especially for pediatric patients, A2143G mutation is responsible for the failure of treatment with a ratio of $50 \%$ and $A 2142 \mathrm{G}$ and $\mathrm{A} 2142 \mathrm{C}$ mutations with a ratio of $20 \%{ }^{29}$.

In the frame of the study we have applied upper GIS endoscopy to the patients who suffered from dyspepsia, abdominal pain, anemia and GIS bleeding, and we have detected H. pylori positivity. Among these patients, clarithromycin resistance was mostly observed for the dyspepsia group, followed by the group having abdominal pain. There was no significant relationship between upper GIS indications and detection of clarithromycin resistance. The fact that clarithromycin resistance was low for the group of abdominal pain and that it was not detected for other patients who went through upper GIS endoscopy for other reasons may be related with the low number of patients in these groups. In a study from Turkey, the most frequent endoscopy indication was abdominal pain for $89.2 \%$ of the patients, and $18.2 \%$ clarithromycin resistance was found ${ }^{17}$. H. pylori positive patients showed very different clinical symptoms and this was considered to be the reason for not being able to establish a relation between H.pylori positivity accompanied by clarithromycin resistance and endoscopy indications. In this study, there was no statistically significant relationship between clarithromycin resistance mutation and gastritis or peptic ulcer. In another study which included only dyspeptic patients, 21.7 $\%$ clarithromycin resistance was detected, but no correlation was found between gastritis, gastric ulcer, duodenal ulcer and gastric cancer and clarithromycin resistance ${ }^{32}$.

In conclusion, the success of $H$. pylori eradication is important with regards to prevention of complications that may develop. Concerning $\mathrm{H}$. pylori eradication, it would be an advantage to know the region's resistance to treatment and mutation type before starting clarithromycin. The tests presenting clarithromycin resistance are not applied routinely at each center. Therefore, the studies carried out are important for obtaining regional data and for determination of that region's treatment strategy. Conclusively, our study revealed that 
clarithromycin resistance was detected to be low for gastric biopsy samples in Manisa region and therefore it can still be the first choice in $H$. pylori eradication treatment. If $H$. pylori eradication fails, clarithromycin resistance, A2143G and A2142G mutations should be considered primary.

\section{REFERENCES}

1. Goodwin CS, Mendall MM, Northfield TC. Helicobacter pylori infection. Lancet 1997; 349: 265-269.

2. Helicobacter pylori in Peptic Ulcer Disease. NIH Consensus Statement 1994; 12: 1-23.

3. Uemura N, Okamoto S, Yamamoto S, et al. Helicobacter pylori infection and the development of gastric cancer. N Engl J Med 2001; 345: 784-789.

4. Dunn BE, Cohen H, Blaser MJ. Helicobacter pylori. Clin Microbiol Rev 1997; 10: 720-741.

5. Ozen A, Ertem D, Pehlivanoglu E. Natural history and symptomatology of Helicobacter pylori in childhood and factors determining the epidemiology of infection. J Pediatr Gastroenterol Nutr 2006; 42: 398-404.

6. Malfertheiner P, Megraud F, O'Morain CA, et al. European Helicobacter Study Group. Management of Helicobacter pylori infection--the Maastricht IV/ Florence Consensus Report. Gut 2012; 61: 646-664.

7. Megraud F. H. pylori antibiotic resistance: prevalence, importance, and advances in testing. Gut 2004; 53: 1374-1384.

8. Malfertheiner P, Megraud F, O'Morain C, et al. Current concepts in the management of Helicobacter pylori infection: the Maastricht III Consensus Report. Gut 2007; 56: 772-781.

9. Kalach N, Benhamou PH, Campeotto F, Bergeret M, Dupont C, Raymond J. Clarithromycin resistance and bacterial eradication of Helicobacter pylori in children. Antimicrob Agents Chemother 2001; 45: 2134-2135.

10. Toracchio S, Marzio L. Primary and secondary antibiotic resistance of Helibocater pylori strains isolated in central Italy during the years 1998-2002. Dig Liver Dis 2003; 35: 541-545.

11. Ahmad N, Zakaria WR, Mohamed R. Analysis of antibiotic susceptibility patterns of Helicobacter pylori isolates from Malaysia. Helicobacter 2011; 16: 47-51.

12. Talebi Bezmin Abadi A, Mobarez AM, Taghvaei T, Wolfram L. Antibiotic resistance of Helicobacter pylori in Mazandaran, North of Iran. Helicobacter 2010; 15: 505-509.

13. Ben Mansour K, Burucoa C, Zribi M, et al. Primary resistance to clarithromycin, metronidazole and amoxicillin of Helicobacter pylori isolated from Tunisian patients with peptic ulcers and gastritis: a prospective multicentre study. Ann Clin Microbiol Antimicrob 2010; 9: 22.

14. Simsek H, Balaban YH, Gunes DD, Hascelik G, Ozarlan E, Tatar G. Alarming clarithromycin resistance of Helicobacter pylori in Turkish population. Helicobacter 2005; 10: 360-361.
15. Onder G, Aydin A, Akarca U, Tekin F, Ozutemiz O, Ilter T. High Helicobacter pylori resistance rate to clarithromycin in Turkey. J Clin Gastroenterol 2007; 41: 747-750.

16. Sezgin O, Aslan G, Altintaş E, Tezcan S, Serin MS, Emekdaş G. Detection of point mutations on 23S rRNA of Helicobacter pylori and resistance to clarithromycin with PCR-RFLP in gastric biopsy specimens in Mersin, Turkey. Turk J Gastroenterol 2008; 19: 163-167.

17. Ozçay F, Koçak N, Temizel IN, et al. Helicobacter pylori infection in Turkish children: comparison of diagnostic tests, evaluation of eradication rate, and changes in symptoms after eradication. Helicobacter 2004; 9: 242-248.

18. Erdur B, Ozturk Y, Gurbuz ED, Yilmaz O. Comparison of sequential and standard therapy for Helicobacter pylori eradication in children and investigation of clarithromycin resistance. J Pediatr Gastroenterol Nutr 2012; 55: 530-533.

19. Karabiber H, Selimoglu MA, Otlu B, Yildirim O, Ozer A. Virulence factors and antibiotic resistance in children with Helicobacter pylori gastritis. J Pediatr Gastroenterol Nutr 2014; 58: 608-612.

20. de Francesco V, Margiotta M, Zullo A, et al. Primary clarithromycin resistance in Italy assessed on Helicobacter pylori DNA sequences by TaqMan realtime polymerase chain reaction. Aliment Pharmacol Ther 2006; 23; 429-435.

21. Street ME, Caruana P, Caffarelli C,et al. Antibiotic resistance and antibiotic sensitivity-based treatment in Helicobacter pylori infection: advantages and outcome. Arch Dis Child 2001; 84: 419-422.

22. Egan BJ, Katicic M, O'Connor HJ, O'Morain CA. Treatment of Helicobacter pylori. Helicobacter 2007; 12: $31-37$.

23. Vakil N. Helicobacter pylori treatment: a practical approach. Am J Gastroenterol 2006; 101: 497-499.

24. Debets-Ossenkopp YJ, Sparrius M, Kusters JG, Kolkman JJ, Vandenbroucke-Grauls CM. Mechanism of clarithromycin resistance in clinical isolates of Helicobacter pylori. FEMS Microbiol Lett 1996; 142: 37-42.

25. Feydt-Schmidt A, Rüssmann $\mathrm{H}$, Lehn $\mathrm{N}$, et al. Fluorescence in situ hybridization vs. epsilometer test for detection of clarithromycin-suspectible and clarithromycin-resistant Helicobacter pylori strains in gastric biopsies from children. Aliment Pharmacol Ther 2002;16: 2073-2079.

26. Oleastro M, Ménard A, Santos A, et al. Real-time PCR assay for rapid and accurate detection of point mutations conferring resistance to clarithromycin in Helicobacter pylori. J Clin Microbiol 2003; 41: 397402.

27. Soltermann A, Perren A, Schmid S, et al. Assessment of Helicobacter pylori clarithromycin resistance mutations in archival gastric biopsy samples. Swiss Med Wkly 2005; 135: 327-332. 
28. Schmitt BH, Regner M, Mangold KA, Thomson RB Jr, Kaul KL. PCR detection of clarithromycin-susceptible and -resistant Helicobacter pylori from formalin-fixed, paraffin-embedded gastric biopsies. Mod Pathol 2013; 26: $1222-1227$.

29. Francavilla R, Lionetti E, Castellaneta S, et al. Clarithromycin-resistant genotypes and eradication of Helicobacter pylori. J Pediatr 2010; 157: 228-232.

30. De Francesco V, Zullo A, Ierardi E, et al. Phenotypic and genotypic Helicobacter pylori clarithromycin resistance and therapeutic outcome: benefits and limits. J Antimicrob Chemother 2010; 65: 327-332.
31. Trespalacios AA, Otero W, Caminos JE, et al. Phenotypic and genotypic analysis of clarithromycin-resistant Helicobacter pylori from Bogotá D.C., Colombia. J Microbiol 2013; 51: 448-452.

32. Abadi AT, Taghvaei T, Ghasemzadeh A, Mobarez AM High frequency of A2143G mutation in clarithromycinresistant Helicobacter pylori isolates recovered from dyspeptic patients in Iran. Saudi J Gastroenterol 2011; 17: 396-399. 